\title{
AVALIAÇÃO MULTICRITERIAL DA QUALIDADE EM SERVIÇOS: UM ESTUDO DE CASO EM UM HOTEL
}

MULTICRITERIA EVALUATION OF QUALITY IN SERVICES: A CASE STUDY OF IN A HOTEL

Recebido em 30.11.2015. Aprovado em 04.10.2016

Avaliado pelo sistema double blind review

DOI: http://dx.doi.org/10.12712/rpca.v10i3.696

\section{Fagner José Coutinho Melo}

fagnerespecial@yahoo.com.br

Universidade Federal de Pernambuco (UFPE), Recife/PE, BRASIL

\section{Taciana de Barros Jerônimo}

taciana.barros@gmail.com

Universidade Federal de Pernambuco (UFPE), Recife/PE, BRASIL

\section{Joás Tomaz de Aquino}

joastomaz@outlook.com

Universidade Federal de Pernambuco (UFPE), Recife/PE, BRASIL

\section{Resumo}

O artigo analisa as variáveis que levam a satisfação da prestação de serviço hoteleiro, utilizando três conceitos: Desdobramento da Função Qualidade (QFD), avaliação do serviço pelo SERVPEF e análise hierárquica de processos (AHP). Pois há uma lacuna deixada por Akao (1990), no QFD que é como analisar a compensação das alternativas entre elas mesmas, de forma que o resultado desta avaliação seja a priorização ou uma ordem de implementação das melhorias do projeto do produto/serviço. Esta lacuna será preenchida com o método AHP, para que ocorra a análise compensatória posicione o hotel de forma mais competitiva em detrimento as empresas concorrentes. Para isso, foi aplicado um questionário com 150 hóspedes e com o gestor do hotel estudo de caso. Após, a coleta de dados foi adotado o QFD que revelou as requisições do cliente, seguido pelo método AHP para priorizar as alternativas de melhoria. A contribuição desta pesquisa é a busca pela adequação dos serviços prestados de acordo com a voz e percepção do cliente destacando o hotel no mercado. E assim, espera-se que os consumidores consigam sentir a melhoria nas dimensões por ele avaliadas como as mais necessárias para a promoção de sua satisfação.

Palavras-chave: Desdobramento da função qualidade. Análise hierárquica de processos. Hotel.

\section{Abstract}

The article analyzes the variables that leads to satisfaction of providing hotel service, using three concepts: Quality Function Deployment (QFD), service evaluation by SERVPEF and hierarchical analysis process (AHP), because there is a gap left by Akao (1990), the QFD which is how to analyze the compensation of alternatives among themselves, so that the result of this evaluation is to prioritize or an order of implementation of product design improvements / service. This gap will be filled with the AHP, for the occurrence of compensatory analysis position the most competitive form of hotel over competing companies. For this, a questionnaire with 150 guests and the manager of the hotel case study was applied. After the data collection was adopted QFD revealed that the client requests, followed by the AHP method to prioritize the improvement alternatives. The contribution of this research is the search for the adequacy of the services provided according to the voice and customer perception highlighting the hotel market. So, it is expected that the consumer can feel the improvement in the dimensions measured by it as the most necessary to promote their satisfaction.

Keywords: Quality function deployment. Hierarchical analysis processes. Hotel. 


\section{Introdução}

A satisfação do consumidor no serviço hoteleiro tem se tornado um importante critério para julgar a qualidade das empresas no setor hoteleiro. Para saber qual o exato grau da satisfação dos serviços prestados por um determinado hotel é preciso aplicar técnicas e ferramentas de aferição para desenvolvêla nos requisitos de elaboração do serviço (Aquino, Jerônimo, \& Melo, 2015). Uma das ferramentas para atingir esse fim é o QFD (Quality Function Deployment) ou casa da qualidade ou voz do cliente que consiste em um método estruturado para traduzir as necessidades dos clientes em requisitos técnicos nos produtos e serviços oferecidos. O processo é considerado como uma ferramenta de engenharia simultânea, pois relaciona ao mesmo tempo os requisitos ou a $\mathrm{VOZ}$ do cliente (o quê) ou as especificações do produto com os parâmetros de design de produto (como), esta correlação é feita com base em uma sequência lógicoracional e de resultados quantitativos (AKAO, 1990).

De acordo com Chambers e Lewis (1989), a qualidade da prestação do serviço de um hotel ocorre quando o consumidor leva em sua memória apenas lembranças positivas de três componentes: bens, atendimento e ambiente. Para Fitzsimmons e Fitzsimmons (2010) e Zeithaml, Parasuraman, e Berry (1985), bens são os elementos tangíveis, como exemplo: móveis, equipamentos, máquinas, dentre outros; atendimento depende do desempenho humano envolvido na operação envolvem elementos intangíveis e subjetivos; e o ambiente concentra elementos (barulho, odor, iluminação) que podem ser controlados para o benefício e o conforto de quem o está utilizando.

Para atingir o objetivo de melhoria do bem-estar físico e psicológico, atendendo as expectativas dos indivíduos, pressupõe-se que as empresas ofertem ambientes que contenham elementos que influenciem positivamente a percepção sobre aquilo que é ofertado (VARGO; LUSCH, 2008). Deste modo, é importante saber mensurar a real percepção da prestação dos serviços de modo a aprimorar e identificar os pontos deficientes no estabelecimento da receptividade do consumidor, em específico os hotéis.

Segundo Castelli (2000), hotel é conceituado como uma edificação que oferece habitações ou apartamentos mobiliados que, mediante o pagamento de diárias, oferece alojamento aos clientes. De acordo com o Instituto Brasileiro de Turismo (EMBRATUR) (2010), o hotel é um estabelecimento com serviço de recepção, alojamento temporário, com ou sem alimentação, ofertados em unidades individuais e de uso exclusivo dos hóspedes, mediante cobrança de diária.

O tipo de serviço e de habitações, qualidade dos serviços, grau de conforto pode ser diferenciado caracterizado conforme o padrão e as características de suas instalações, localização e grau de entretenimento e comodidade em suas instalações, para as normas da EMBRATUR (2010), os hotéis podem ser classificados em 5 estrelas, 4 estrelas, 3 estrelas, 2 estrelas ou 1 estrela. A importância do setor hoteleiro no Brasil se mostra a partir da geração de 31.729 empregos diretos, em 5.036 estabelecimentos existentes com capacidade total de 373.673 leitos disponibilizados no ano de 2011 (Instituto Brasileiro de Geografia e Estatística [IBGE], 2012).

Para Normann (1993), o próprio cliente é parte do sistema de produção dos serviços deste setor, atuando em forma de cooperativa junto aos colaboradores. Desta forma, um hotel deve oferecer para seus hóspedes ambientes agradáveis e funcionais, com qualidade no serviço prestado por parte de todos os seus funcionários. Todos os elementos devem estar inter-relacionados para formar na memória do cliente a qualidade da prestação de serviço (Silva, Medeiros, \& Costa, 2009), que neste caso pode ser atribuída a momentos de lazer, em que o consumidor é o intérprete de sua experiência de consumo.

Por isto, este artigo visa identificar as variáveis que levam um cliente à satisfação da prestação de serviço de um hotel, por meio de uma abordagem de três conceitos: Desdobramento da Função Qualidade (QFD), avaliação do serviço pelo SERVPEF e análise hierárquica de processos (AHP). A ferramenta QFD será usada para direcionar os esforços em direção da diminuição da discrepância entre as percepções do consumidor e suas expectativas sobre o desempenho do serviço hoteleiro (GARVIN, 1988; PARASURAMAN, ZEITHAML e BERRY, 1988). A análise hierárquica de processos será utilizada para priorizar qual alternativa de melhoria da qualidade é a mais adequada e urgente na visão do consumidor. E o SERVPERF tem objetivo de coletar dados para esta análise holística de implementação e operacionalização das atividades para a garantia da prestação de serviço 
em um hotel, que traga satisfação ao consumidor. Dentro deste contexto, esta pesquisa tem o objetivo de elucidar o seguinte questionamento: Quais fatores são levados em consideração por um cliente durante a prestação do serviço para que haja satisfação?

\section{Fundamentação teórica}

\section{Desdobramento da função qualidade}

O QFD é uma ferramenta estruturada que se propõe revelaras requisiçõesdoclienteemespecificaçõestécnicas apropriadas para cada etapa do desenvolvimento do serviço. Para a implementação desta ferramenta, Akao (1990) e Cardoso, Filho e Miguel (2015) indicam que devem ocorrer em duas etapas, são elas: (i) na etapa do projeto - interpretação das características de qualidade apontadas pelos clientes em dois fluxos de processos de informações: externas - prospectadas e captadas em pesquisas com os consumidores; internas - para a operacionalização técnica dos requisitos solicitados, bem como os dados da avaliação da concretização dos requisitos em uma nova maneira de prestar o serviço na prática. (ii) na etapa da garantia da qualidade - amplia a responsabilidade e comprometimento pelo uso do QFD para todos os colaboradores, pois cada ação ou atividade exercida por um dos membros de uma empresa pode influenciar nos resultados dos serviços produzidos.

O QFD é uma articulação do relacionamento dos fatores: (o quê) versus (como), através da construção da matriz de planejamento. Para a construção dessa matriz é fundamental ter certeza de que as decisões de design de produtos são baseadas no cliente e não no que é percebido como as necessidades do cliente. Porém uma lacuna deixada por Akao (1990) é como analisar a compensação das alternativas entre elas mesmas, de forma que o resultado desta avaliação seja a priorização ou uma ordem de implementação das melhorias do projeto do produto/serviço. Outros autores como Clausing (1993), Lockamy e Khurana (1995), Sullivan (1986) estudaram e propuseram alternativas ao uso do QDF, mas não avaliaram a importância intercritério das alternativas.

O objetivo principal do QFD é tentar assegurar que o projeto final do produto ou serviço realmente atenda às necessidades dos clientes. As vantagens através da utilização de QFD incluem uma redução no tempo necessário para a concepção do produto, dos custos associados com este processo, pela redução do número de correções e erros de concepção (CHUN; CHO, 2015).

\section{A análise hierárquica de processos (AHP)}

A análise hierárquica de processos (AHP) é um método de apoio à decisão desenvolvido pelo autor Thomas L. Saaty, em 1980, que tem por objetivo hierarquizar a estruturação do problema, ou seja, para priorização das alternativas em um problema (SAATY, 1980 E 1990). O AHP é um método de critério único de síntese, que provê medidas de consistência das preferências e seu uso é apropriado tanto para decisões individuais, quanto para grupos de decisão. Esse método define quantitativamente a relação de importância entre pares de elementos por meio de uma escala de razão que varia de 0 (zero) até o valor 9 (nove) (ENSSLIN, MONTIBELLER NETO E NORONHA, 2001; CHOW, 2005; VELJKO, SENI, E MIMOVI, 2015), conforme está apresentado na Tabela 1.

Tabela 1. Escala Numérica de Saaty

\begin{tabular}{|c|c|c|}
\hline $\begin{array}{c}\text { Escala } \\
\text { Numérica }\end{array}$ & Escala Verbal & Explicação \\
\hline 1 & $\begin{array}{l}\text { Ambos elementos } \\
\text { são de igual } \\
\text { importância. }\end{array}$ & $\begin{array}{l}\text { Ambos elementos } \\
\text { contribuem com } \\
\text { a propriedade de } \\
\text { igual forma. }\end{array}$ \\
\hline 3 & $\begin{array}{l}\text { Moderada } \\
\text { importância de um } \\
\text { elemento sobre o } \\
\text { outro. }\end{array}$ & $\begin{array}{l}\text { A experiência e a } \\
\text { opinião favorecem } \\
\text { um elemento sobre } \\
\text { o outro. }\end{array}$ \\
\hline 5 & $\begin{array}{l}\text { Forte importância } \\
\text { de um elemento } \\
\text { sobre o outro. }\end{array}$ & $\begin{array}{l}\text { Um elemento } \\
\text { é fortemente } \\
\text { favorecido. }\end{array}$ \\
\hline 7 & $\begin{array}{l}\text { Importância } \\
\text { muito forte de um } \\
\text { elemento sobre o } \\
\text { outro. }\end{array}$ & $\begin{array}{l}\text { Um elemento é } \\
\text { muito fortemente } \\
\text { favorecido sobre o } \\
\text { outro. }\end{array}$ \\
\hline 9 & $\begin{array}{l}\text { Extrema } \\
\text { importância de um } \\
\text { elemento sobre o } \\
\text { outro. }\end{array}$ & $\begin{array}{l}\text { Um elemento é } \\
\text { favorecido pelo } \\
\text { menos com } \\
\text { uma ordem de } \\
\text { magnitude de } \\
\text { diferença. }\end{array}$ \\
\hline
\end{tabular}




$\begin{array}{lll}\text { Valores } & \text { Usados como } \\ \text { 2, 4, 6 e } 8 & \begin{array}{l}\text { intermediários } \\ \text { entre as opiniões } \\ \text { adjacentes. }\end{array} & \text { valores de consenso } \\ \text { entre as opiniões. }\end{array}$

Fonte: Saaty (1980).

A aplicação do método AHP, segundo Saaty (2001), envolve três etapas, a saber:

(1) Definição e estruturação do problema: nesta etapa são definidos o objetivo ou meta do problema, os critérios e os subcritérios para a construção de uma rede hierárquica que possa representar fidedignamente um problema de decisão. As opções de ação do problema são mutuamente exclusivas e devem convergir para o objetivo ou meta, conforme está ilustrado na Figura 1.

Figura 1 . Estruturação do problema em diagrama hierárquico

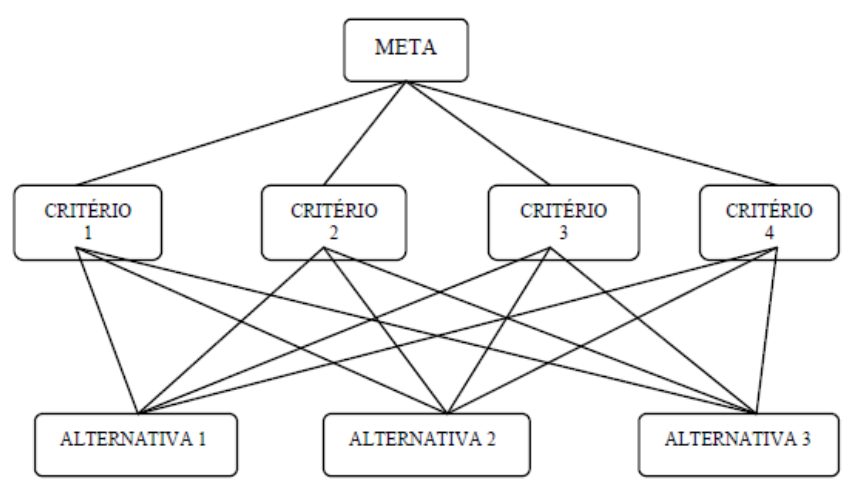

Fonte: Ferreira (2006).

(2) Definição de prioridades: nesta etapa são construídas as matrizes A (quadradas) de comparações ( $\mathrm{n} \times \mathrm{n}$ ), nela as linhas e colunas correspondem aos $\mathrm{n}$ critérios analisados. A comparação é feita a partir dos julgamentos realizados (aij) com as pessoas envolvidas a partir da escala numérica de Saaty (Tabela 1), esse valor obtido representa a importância relativa ou o peso do critério da linha $i$ com relação ao critério da coluna $j$. Para isso, são necessários $n(n-1) / 2$ julgamentos para uma matriz $\mathrm{n} \times \mathrm{n}$, sendo $n$ o número de linhas e de colunas ou de elementos pertencentes a esta matriz. Nesta etapa é mensurado o peso composto para cada alternativa baseada em preferências derivadas da matriz de comparação. Os elementos da matriz A são definidos pelas seguintes condições:

$A=\left[\begin{array}{cccc}1 & a_{12} & \ldots & \left.a_{1 n}\right\rceil \\ 1 & a_{12} & \ldots & a_{1 n} \\ 1 / a_{21} & 1 & \ldots & a_{2 n} \\ \ldots & \ldots & \ldots & \ldots \\ 1 / a_{n 1} & 1 / a_{n 2} & \ldots & 1\end{array}\right] \quad$ onde:

Nessa matriz, as posições da diagonal serão sempre 1 , tendo em vista que um elemento é igualmente importante a ele mesmo. Para preencher os outros elementos da matriz fora da diagonal, fazemse os julgamentos e determina-se a intensidade de importância de acordo com a Tabela 1. Para as comparações inversas, isto é, na parte inferior esquerda da matriz, colocam-se os valores recíprocos dos da parte superior direita da mesma (SILVA, 2007).

Saaty (1980) propôs vários métodos para normalização dos dados da matriz, dentre eles, nesse estudo realizouse primeiramente a soma dos elementos de cada coluna das matrizes de julgamento e posteriormente dividiuse cada elemento das matrizes pelo somatório dos valores da respectiva coluna. Nesta etapa são calculadas as prioridades médias locais que são as médias das linhas da matriz normalizada e as prioridades globais ou os vetores de prioridades $(\lambda)$ que associada a cada alternativa a sua postura hierárquica em relação à meta principal.

(3) Análise de consistência lógica: verifica a consistência ou validade da coerência nas comparações elaboradas. A inconsistência pode surgir quando algumas comparações se contradizem umas com as outras, desta forma o método AHP se propõe a calcular a Taxa ou Razão de Consistência (RC) dos julgamentos, que é representada por:

$R C=\frac{I C}{I R}$

Onde IR = Índice de Consistência Randômico obtido para uma matriz recíproca de ordem $n$, com elementos não negativos, este fator é gerado randomicamente $\mathrm{e}$ está apresentado na Tabela 2. 
Tabela 2 . Índices de Consistência Randômico (RI)

\begin{tabular}{ccccccccccc}
\hline $\mathrm{n}$ & 1 & 2 & 3 & 4 & 5 & 6 & 7 & 8 & 9 & 10 \\
\hline $\mathrm{RI}$ & 0 & 0 & 0,58 & 0,90 & 1,12 & 1,24 & 1,32 & 1,41 & 1,45 & 1,49 \\
\hline
\end{tabular}

Fonte: Saaty (1980).

E, o Índice de Consistência (IC) é dado por (Equação 2):

$I C=\frac{\lambda_{\operatorname{máx}}-n}{n-1}$

Onde: $\lambda_{\text {máx }} \lambda_{\text {máx }}=$ maior valor de autovetor da matriz de julgamentos.

Segundo Saaty (2001), se a razão de consistência for menor do que 0,1 pode-se afirmar que há consistência para prosseguir com os cálculos do AHP a condição de consistência dos julgamentos está preservada. Caso contrário, se $\mathrm{RC} \geq 0,10$, os julgamentos devem ser refeitos até que a inconsistência seja atenuada (SAATY, 2008).

\section{Método de Pesquisa}

A pesquisa é formatada como estudo de caso (YIN, 2015), tem caráter descritivo visando identificar a estruturação da qualidade utilizando a ferramenta do QFD. Descreve a percepção da prestação do serviço vivenciada pelos clientes no hotel. Este estudo de caso foi feito em um hotel, pois parte do pressuposto que o consumidor exerce o papel de usuário, justificado pelos seguintes fatores: (i) o consumidor é co-elaborador do serviço, ele recebe e se beneficia do serviço, precisa do atendimento direto dos funcionários; (ii) a empresa elabora ações e atividades que auxiliam e apoiam a estadia do consumidor, de forma que promova maior qualidade, ou seja, que tenha credibilidade de elaborar o serviço como ele está descrito (no ato da reserva) e que a infraestrutura dê conforto máximo ao hóspede. Para que uma determinada empresa do ramo hoteleiro participasse dessa pesquisa, foram aplicados os seguintes parâmetros e requisitos:

a) O hotel deve estar localizado em Pernambuco, pois, este trabalho tem o intuito de desenvolver o local em que os pesquisadores estão inseridos;

b) O hotel estar cadastrado pela EMBRATUR;

c) O hotel deve possuir tempo de atuação mais do que 5 (cinco) anos;

d) O hotel não deve possuir tradição de avaliar a qualidade na prestação de seu serviço. 
Deste modo, o hotel estudo de caso analisado está localizado em Pernambuco, mas terá seu nome e endereço preservado por motivos de confidencialidade e sigilo sobre todas as informações técnicas e outras relacionadas à empresa. Também serão preservados os nomes dos hóspedes e dos hotéis A e B que fizeram parte deste trabalho.

A escolha pelo método de pesquisa estudo de caso se deu pela capacidade de elaborar um estudo mais aprofundado e detalhado o que permite melhor conhecimento dos processos e das relações sociais (DENCKER, 2008; MORGAN \& SMIRCICH, 1980; YIN, 2015). Segundo Godoy (2010, p. 120), “o estudo de caso usa dados coletados em uma ou mais organizações, ou grupos dentro das organizações, visando prover uma análise do contexto e dos processos envolvidos no fenômeno em estudo". Ou seja, a coleta de dados foi realizada a partir de várias fontes (entrevistas, observação in loco - da situação tangível e do comportamento dos hóspedes e funcionários quanto ao hotel, documentos dentre outros) resultando em uma descrição densa do contexto, da história, dos processos, relações e eventos que caracterizam o hotel. $\mathrm{O}$ estudo pode ser classificado, ainda, como uma pesquisa aplicada, pois aplica os conhecimentos em um determinado hotel, através de questionários que está apresentado no Apêndice 1.

O hotel do presente estudo de caso possui um gestor e 20 (vinte) funcionários. Ele é de pequeno porte, possui 206 apartamentos, sendo 123 na categoria padrão; 48 na categoria de quarto Executivo; 28 na de luxo (suíte) e sete apartamentos projetados para atender hóspedes com necessidades especiais. Possui estrutura completa para eventos e ambientes reservados para eventos de negócios. As habitações possuem ar-condicionado, telefone, TV a cabo, internet sem fio, frigobar, cofre, cama box, dentre outros equipamentos hoteleiros. Ainda oferece ao hóspede uma piscina, uma sauna e uma área de playground para as crianças elaborarem atividades ao ar livre.

A análise dos dados foi elaborada de forma conjunta, em que houve a avaliação e confronto dos dados em dois momentos: (i) os fatos e as evidências relativas a cada entrevistado - hóspede e gestor, no conjunto das suas respostas; (ii) visualização dos elementos da pesquisa em observação in loco (MATTOS, 2010). Sendo, o primeiro momento, o mais importante para a produção dos resultados gerais desta análise. Neste sentido, foram coletados os dados primários sobre as opiniões de 150 hóspedes e do gestor do hotel. Pois, avaliar apenas o diário de ocorrências e o livro de reclamações do hotel não é suficiente para identificar as situações que promovem a satisfação ou a insatisfação do serviço, quais os pontos a serem melhorados e qual a ordem de importância de melhoria na visão do consumidor, pois é ele quem sentirá a implementação destas melhorias estruturais e gerenciais do hotel estudo de caso.

A elaboração do questionário teve como base o modelo SERVPERF de avaliação do serviço prestado. Pois, ele retrata melhor as variações de qualidade em relação ao desempenho do serviço prestado, ele avalia a qualidade da percepção do que foi realmente elaborado (CRONIN \& TAYLOR, 1992; BOLTON e DREW, 1991), dentro das cinco dimensões da qualidade de um serviço, propostas por Parasuraman, Zeithaml, \& Berry (1985), são elas: (i) credibilidade; (ii) tangibilidade; (iii) presteza; (iv) segurança; (v) empatia.

O questionário utilizado nesta pesquisa possui duas partes, a primeira delas trata do SERVPERF, que é composto de 22 questões que avaliam as cinco dimensões anteriormente descritas. Ele foi aplicado momento do check-out com os hóspedes acima de 18 anos. Cada hóspede colocou uma nota dentro da escala Likert, que varia de 1 até 5 pontos referente ao grau de satisfação do serviço prestado, onde: 1- Totalmente insatisfeito; 2- Ligeiramente satisfeito; 3- Pouco satisfeito; 4- Muito satisfeito e 5- Extremamente satisfeito. A segunda seção do questionário contém uma questão sobre o grau de satisfação do consumidor quando se compara usando a escala de Likert com valores de 1- Totalmente insatisfeito e 5- Extremamente satisfeito, o hotel estudo de caso em comparação a dois hotéis da localidade e escolhidos pelo próprio cliente. Esta avaliação corresponde ao nível do posicionamento competitivo da empresa frente aos seus concorrentes, que irá compor a avaliação competitiva na matriz QFD. Para a composição do QFD foi pesquisado a dificuldade técnica e a área da matriz como x como com os funcionários e o gestor do hotel em estilo de brainstorming, eles opinavam e atribuíam os pontos para cada ação de melhoria, esta foi obtida através da resposta aos seguintes questionamentos: (i) como a empresa pode atender a este requisito do consumidor?; (ii) qual a dificuldade técnica, em escala de 1 a 5 para 
implementar o requisito do consumidor em serviço do hotel?

Em seguida, foi utilizado o método AHP para o estabelecimento da importância relativa que contribuirá na priorização dos elementos requisitados pelo consumidor e de como devem ser as características do serviço hoteleiro para melhor servir seu hóspede. Esta etapa foi elaborada com o gestor em estilo de brainstorming, pela resposta aos seguintes questionamentos: (i) Se melhorar essa característica da qualidade, as outras melhoram, pioram ou são irrelevantes? (ii) Qual a importância do requisito do consumidor em comparação à característica da qualidade, use a escala de Saaty? Após a coleta dos dados, foi elaborada a matriz QFD, possibilitando à empresa focar em melhorias de seu serviço prestado nos requisitos mais importantes sob o julgamento do consumidor.

\section{Resultados do Estudo de Caso}

\section{Análise SERVPERF}

A amostra é composta por indivíduos casados com média de 2,7 filhos; na qual, 67\% são homens e $33 \%$ são mulheres, de faixa etária média de 42 anos. A amostra também demonstrou elevado nível de instrução, pois cerca de $90 \%$ dos entrevistados são pós-graduados, e possuem diferentes profissões, entre elas tem-se: advogados, professores, médicos, engenheiros, procuradores, farmacêuticos. Na Tabela 3 pode-se observar a percepção dos clientes com relação ao desempenho na prestação do serviço do hotel estudo de caso.

Tabela 3 . Média por Dimensão da Avaliação de Serviço do Hotel

\begin{tabular}{cccc}
\hline $\begin{array}{c}\text { Nome da } \\
\text { Dimensão }\end{array}$ & Questões & $\begin{array}{c}\text { Média da } \\
\text { Dimensão }\end{array}$ & $\begin{array}{c}\text { Desvio- } \\
\text { Padrão da } \\
\text { Dimensão }\end{array}$ \\
\hline Tangíveis & $1-4$ & 3,8 & 0,331662 \\
Credibilidade & $5-9$ & 3,6 & 0,2 \\
Presteza & $10-13$ & 4,1 & 0,08165 \\
Segurança & $14-17$ & 3,8 & 0,330404
\end{tabular}

ISSN 1982-2596

\begin{tabular}{llll} 
Empatia & $18-22$ & 3,8 & 0,339116 \\
\hline
\end{tabular}

Fonte: Os autores (2015).

A seguir tem-se uma análise mais aprofundada de acordo com cada dimensão da percepção da qualidade do hotel identificada pela amostra.

A) Dimensão Tangibilidade: Observou a obsolescência de alguns equipamentos como: móveis, chuveiro elétrico, televisão. Entretanto as instalações físicas são satisfatórias tanto dos quartos quanto de outras áreas do hotel. Há a realização de manutenção preventiva nos equipamentos, já que a rotatividade de cada quarto não é alta, outros tipos de manutenção, como troca de fiação e cabos de eletricidade é feita em períodos de baixa estação, tempo necessário para testar e adequar os equipamentos no momento em que o quarto está totalmente vago.

B) Dimensão Credibilidade: foi constatado que os funcionários são atentos, porém quando solicitados são lentos para atender as necessidades dos clientes, causando irritação, insatisfação e por isso obteve a pior avaliação do desempenho do serviço. Outro ponto importante é a atenção a clientes prioritários como idosos e pessoas com necessidades especiais que varia de acordo com o envolvimento emocional do funcionário em prestar o serviço. Ou seja, as pessoas que precisam deste tipo de atendimento são priorizadas de acordo com o envolvimento de cada funcionário, se ele perceber que deve priorizar o atendimento, ele o faz primeiramente e os demais consumidores ficam esperando pelo seu atendimento.

C) Dimensão Presteza: é o empenho dos funcionários em atender os clientes com agilidade e presteza que foi avaliado com média 4,1 e com desvio padrão de 0,08165 pontos. Há evidência da necessidade de melhor preparação dos funcionários no atendimento aos clientes, pois a mão de obra é local formada por moradores vizinhos ao hotel, e a maioria deles só possui o ensino fundamental como o maior nível de instrução.

D) Dimensão Segurança: a personalização do atendimento individual é bastante valorizada pelo hotel, a média desta dimensão foi 3,8 revelando a sua eficiência do atendente seguindo os padrões necessários de tratamento ao cliente. Este valor 3,8 
é referente à formação de uma baixa percepção de risco pelo cliente, à habilidade de transmitir confiança, de ter educação, de cumprir as tarefas de forma correta pelos funcionários. Ou seja, os clientes acreditam nos empregados do hotel com valoração de 3,8 pontos e com desvio padrão de 0,330404 pontos.

E) Dimensão Empatia: A média da dimensão foi 3,8 (e desvio padrão de 0,339116 pontos) que demonstra que mesmo não sendo bem treinado, não possuindo grau de instrução elevado, o atendimento ao consumidor está em nível adequado. Este valor pode ser um reflexo da quantidade insuficiente de funcionários para o atendimento dos clientes em épocas de grande movimentação. Isso mostra que parte do serviço possui ocorre com alguma pendência e está gerando a não satisfação aos consumidores, como exemplo a falta de habilidade para a negociação de problemas de atendimento levantados pelos clientes. Uma característica importante é o incentivo à participação dos colaboradores na prestação de serviço, eles precisam estar sintonizados à qualidade do serviço, é preciso que eles entendam os seus papéis e suas atividades na empresa. Pois, a qualidade está associada à percepção de excelência que ocorre na interação entre cliente e funcionário do hotel.

\section{Desenvolvimento da matriz QFD da empresa}

Em seguida, após a aplicação do questionário foi elaborada a matriz QFD com o gestor (Figura 2), foi solicitado que ele apresentasse quais eram as principais alternativas para atender as solicitações dos consumidores, são eles: A1- treinamento dos funcionários; A2- compra de móveis, equipamentos e máquinas novas; A3- instalação da rede de telefone PABX; A4- melhoria da manutenção preventiva; A5- contratação de funcionários e uso de ferramentas de marketing para melhorar o relacionamento empresa-cliente; A6- parceria com fornecedores mais confiáveis de alimentos e bebidas. Esta é a etapa de relacionamento da qualidade demandada com as características de qualidade do hotel, bem como o preenchimento da matriz da qualidade, de dois elementos de avaliação: (i) relação do quê versus como para a composição da matriz de relações ou da parte central da matriz QFD; (ii) avaliação de como versus como, que é a matriz de correlações, a parte de cima ou o teto da matriz. Desta forma, foram estabelecidas quais são as características de qualidade que o hotel pretende trabalhar.

Figura 2 . Matriz QFD do Hotel Estudo de Caso

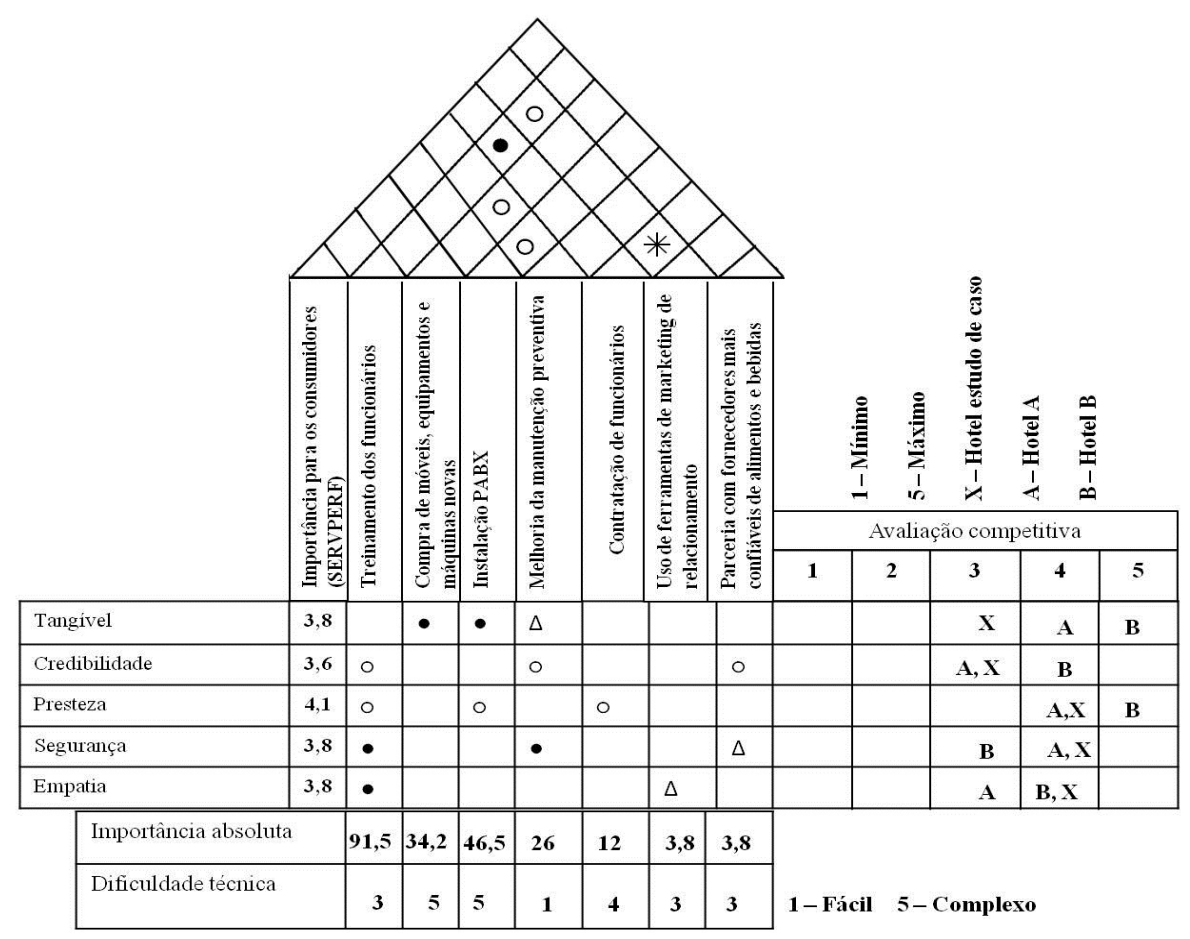

Fonte: Os autores (2015). 
Legenda: • = relação forte $(9$ pontos $) ; \circ=$ relação média ( 6 pontos); $\Delta=$ relação fraca ( 3 pontos); $\mathbf{~ = ~}$ relação negativa (sem pontuação).

Na Figura 2, pode-se observar a importância absoluta para cada como, o treinamento dos funcionários deteve a maior relação com 91,5 pontos, em seguida instalação da central $\mathrm{PABX}$ (46,5 pontos), compra de móveis, equipamentos e máquinas novas (34,2 pontos), melhoria da manutenção preventiva (26 pontos), contratação de funcionários (12,3 pontos), uso de ferramentas de marketing de relacionamento e parceria com fornecedores mais confiáveis de alimentos e bebidas, ambos com 3,8 pontos de importância absoluta, segundo a avaliação dos clientes e gestor. Após a importância absoluta, a linha abaixo é a avaliação da dificuldade técnica da implementação de cada alternativa para a melhoria do serviço, pode-se observar que o gestor considera complexo a instalação do PABX, de fácil melhoria da manutenção.

Após esta avaliação, era solicitado no questionário apresentado aos consumidores a comparação com outros 2 hotéis os quais localizam se próximo ao hotel estudo de caso, e que são os principais concorrentes para o hotel em estudo de caso. Esta comparação foi possível, uma vez que todos os participantes moram no Estado onde foi realizada a pesquisa, conhecem os hotéis analisados. Neste sentido, pode-se observar que a avaliação competitiva do hotel estudo de caso (X) em comparação a dois hotéis da localidade (A e B) não está ruim em termos de posicionamento de mercado, como esta apresentada na Figura 2 e na Tabela 4. Estas notas que variam de 1 até 5 indicam que o desempenho da empresa, na maioria das dimensões do serviço possui valor médio de 3,4 pontos, enquanto a empresa A possui média de 3,6 pontos e a empresa B possui média de 4,2 pontos.

Tabela 4 . Avaliação comparativa das empresas concorrentes para com a empresa estudo de caso

\begin{tabular}{cccc}
\hline Dimensões & $\begin{array}{c}\text { Empresa } \\
\text { A }\end{array}$ & $\begin{array}{c}\text { Empresa } \\
\text { B }\end{array}$ & $\begin{array}{c}\text { Empresa } \\
\text { X }\end{array}$ \\
\hline Tangibilidade & 4 & 5 & 3 \\
Credibilidade & 3 & 4 & 3 \\
Presteza & 4 & 5 & 4 \\
Segurança & 4 & 3 & 4
\end{tabular}

\begin{tabular}{|c|c|c|c|}
\hline Empatia & 3 & 4 & 3 \\
\hline Média & 3,6 & 4,2 & 3,4 \\
\hline
\end{tabular}

Fonte: Os autores (2015).

Ou seja, segundo os consumidores a empresa $\mathrm{X}$ possui desempenho inferior ao hotel $\mathrm{B}$, nas dimensões tangibilidade e presteza, enquanto nas outras dimensões, o hotel $\mathrm{X}$ possui média estatisticamente significativa semelhante os hotéis A e B. A partir da definição do relacionamento entre os itens de qualidade demandada e as características de qualidade, foi determinada a importância relativa de cada característica de qualidade, para esta determinação foi utilizado o método AHP que será descrito na seção a seguir.

\section{Avaliação do serviço pela análise AHP}

Esta é a etapa em que foi elaborada a composição do vetor de prioridade pela aplicação do método AHP, que foi feita segundo o direcionamento fornecido pelo autor Shimizu (2010). Para isto, foi solicitado que o gestor do hotel comparasse par a par as alternativas elencadas para cada um dos critérios estabelecidos, atribuindo um valor numérico em acordo com a Escala de Saaty, conforme a Tabela 1. Estas alternativas são os elementos como, da matriz QFD, são eles: treinamento dos funcionários; compra de móveis, equipamentos e máquinas novas; instalação da rede de telefone PABX; melhoria da manutenção preventiva; contratação de funcionários; uso de ferramentas de marketing para melhorar o relacionamento empresa-cliente; parceria com fornecedores mais confiáveis de alimentos e bebidas. E, os critérios que foram avaliados na decisão em ordem de importância, pela escala SERVPERF, são as cinco dimensões da qualidade de um serviço são elas: credibilidade; tangibilidade; presteza; segurança; empatia. Com o estabelecimento das alternativas e a ordem de importância de cada critério pode-se chegar a uma solução entre a escolha das alternativas que leva à obtenção da meta estipulada: satisfação do consumidor.

Para o procedimento de normalização pelo método AHP, foi utilizado o método da soma das células divididas pelo valor global da coluna, como proposto por Saaty (1980). Em seguida foi obtido a prioridade de cada alternativa obtida pela média aritmética dos 
valores da linha de cada uma das cinco dimensões da Figura 2. Isto resulta no autovetor de prioridades relativas para ordenação pela soma da coluna dos dados (o quê versus como). Na Tabela 5 estão os valores da importância relativa para cada alternativa e o ranking ou a ordem em que cada uma delas deve ser implementada para a satisfação do cliente pelo serviço do hotel.

Tabela 5 . Avaliação da importância relativa para a prestação do serviço do hotel

\begin{tabular}{lcc}
\hline \multicolumn{1}{c}{ Alternativas } & $\begin{array}{c}\text { Importância } \\
\text { Relativa }\end{array}$ & Ranking \\
\hline $\begin{array}{l}\text { A1 - Treinamento } \\
\text { dos funcionários }\end{array}$ & 0,1674938 & $2^{\circ}$ \\
$\begin{array}{l}\text { A2 - Compra } \\
\text { de móveis, } \\
\text { equipamentos e } \\
\text { máquinas novas }\end{array}$ & 0,03662189 & $6^{\circ}$ \\
$\begin{array}{l}\text { A3 - Instalação da } \\
\text { rede de telefone }\end{array}$ & 0,02314538 & $7^{\circ}$ \\
$\begin{array}{l}\text { PABX } \\
\text { A4 - Melhorias } \\
\text { da manutenção } \\
\text { preventiva }\end{array}$ & 0,1019081 & $5^{\circ}$ \\
$\begin{array}{l}\text { A5 - Contratação de } \\
\text { funcionários }\end{array}$ & 0,35038932 & $1^{\circ}$ \\
$\begin{array}{l}\text { A6 - Uso de } \\
\text { ferramentas de } \\
\text { marketing para } \\
\text { melhorar o } \\
\text { relacionamento } \\
\text { empresa-cliente }\end{array}$ & 0,15872337 & \\
$\begin{array}{l}\text { A7 - Parceria } \\
\text { com fornecedores } \\
\text { mais confiáveis de } \\
\text { alimentos e bebidas }\end{array}$ & 0,16171815 & $4^{\circ}$ \\
\hline
\end{tabular}

Fonte: Os autores (2015).

As prioridades relativas indicam que contratação de funcionários $(0,35038932)$ e treinamento dos funcionários $(0,1674938)$ são as principais alternativas para a melhoria da prestação do serviço para o cliente, o posicionamento da empresa quanto a questão de aperfeiçoamento dos funcionários é válida já que a dimensão presteza foi valorada como a mais importante para os clientes.

Posteriormente, para testar a consistência dos dados da Tabela 4, foi elaborada a análise de consistência das prioridades relativas, segundo o direcionamento do autor (Shimizu, 2010). O índice de consistência (IC) é elaborado a partir da estimativa do autovetor da matriz paritária, que é obtido através da média aritmética dos elementos do vetor de consistência, ou conforme a Equação 2. Calculando com os dados acima se verificou que IC tem valor de 0,417179 pontos.

Em seguida foi calculada a taxa ou razão de consistência (RC) da Equação 1 com os dados do IC e com o RI. A $\mathrm{RC}$ analisa se os valores de julgamento da percepção dos consumidores e do gestor foram bem elaborados na mente dos entrevistados, a taxa obtida foi de 0,316045. Sabe-se que a taxa de consistência deve ser considerada aceitável, quando ela possui valor menor ou igual a 0,10 pontos. Portanto, os julgamentos do gestor e dos clientes possuem alguma incoerência, mas essa limitação não diminui a importância deste estudo (SAATY, 1980).

A dimensão de maior valor (presteza) foi usada para a análise de sensibilidade, para interpretar a classificação obtida pelos critérios, observou-se que ambas as dimensões tiveram a sua importância relativa reduzida drasticamente em $40 \%$ para comprovar se as alternativas (contratação de funcionários e treinamento dos funcionários e Parceria com fornecedores mais confiáveis de alimentos e bebidas) manteriam sua ordem de importância. Após os cálculos, foi observado que esta alteração não modificou a ordem de importância entre as alternativas.

\section{Análise dos resultados}

O gerenciamento das empresas hoteleiras não deve ser focado apenas com base em resultados financeiros e econômicos, tendo em vista que essas são medidas bastante escassas e não acompanham as intempéries mercadológicas, as restrições e as exigências dos clientes. Este setor é marcado por elevadas expectativas por parte dos clientes, já que eles vivenciarão momentos de lazer.

Neste sentido, o modelo aplicado neste trabalho 
expõe a visão do que os clientes realmente desejam para o serviço hoteleiro em ordem de importância das dimensões da qualidade. Esta categorização pode ser entendida como o diagnóstico da qualidade do serviço prestado pela utilização da escala SERVPERF. Com a identificação das dimensões mais valoradas pelos consumidores, trouxe mais informações para a elaboração de quais alternativas de ação de melhoria interna devem ser feitas. E a seguir, estas alternativas deverão ser analisadas de forma estratégica pelos gestores de acordo com a adequação de recursos internos, como eles influenciarão na prestação do serviço hoteleiro. Para isso deve-se priorizar quais as ações que possuem internamente maior peso ou importância que as demais, as de maior peso deverão ser implementadas primeiro.

Foi observado que para a satisfação do cliente no serviço do hotel estudo de caso, obteve-se a composição da importância para cada alternativa, a saber: contratação de funcionários (0,35038932), treinamento dos funcionários $(0,1674938)$, parceria com fornecedores mais confiáveis de alimentos e bebidas $(0,16171815)$, uso de ferramentas de marketing para melhorar o relacionamento empresa-cliente $(0,15872337)$, melhoria da manutenção preventiva (0,1019081), compra de móveis, equipamentos e máquinas novas $(0,03662189)$ e instalação da rede de telefone PABX $(0,02314538)$.

É importante perceber que o ranking fornecido pelo uso do AHP modificou a ordem de implementação se o gestor utilizasse apenas as informações da importância absoluta para a gestão do serviço do hotel, a seguir tem-se a Tabela 6 , que compara as duas avaliações de importância para o direcionamento dos esforços da empresa.

Tabela 6 . Comparação entre as Avaliações da Importância Relativa e Absoluta

\begin{tabular}{ccc}
\hline & Ranking de & Ranking de \\
Alternativas & $\begin{array}{c}\text { Importância } \\
\text { Relativa }\end{array}$ & $\begin{array}{c}\text { Importância } \\
\text { Absoluta }\end{array}$ \\
\hline
\end{tabular}

$\begin{array}{lll}\begin{array}{l}\text { A1 - Treinamento } \\ \text { dos funcionários }\end{array} & 2^{\circ} & 1^{\circ}\end{array}$

A2 - Compra

de móveis, equipamentos $\mathrm{e}$

$6^{\circ}$

$3^{\circ}$

máquinas novas

A3 - Instalação da

rede de telefone

PABX

A4 - Melhorias
da manutenção
preventiva

$5^{\circ}$

$4^{\circ}$

A5 - Contratação

de funcionários

$1^{\circ}$

$5^{\circ}$

A6 - Uso de

ferramentas de

marketing para

melhorar o

$4^{\circ}$

$6^{\circ}$

relacionamento

empresa-cliente

A7 - Parceria

com fornecedores

mais confiáveis de

$3^{\circ}$

$6^{\circ}$

Fonte: Os autores (2015).

Porém, uma limitação encontrada por este trabalho está quanto ao uso do método AHP, pode-se verificar que o RC dos julgamentos do gestor teve o valor de 0,316045, mas sabe-se que segundo Saaty (2008) este índice quando é $\mathrm{RC} \geq 0,10$, os julgamentos devem ser refeitos até que a inconsistência seja atenuada. Desta forma, o mais prudente é refazer a comparação par a par, mas o gestor não se mostrou disponível para outras reuniões.

Desta forma, os esforços operacionais serão elaborados no intuito de melhorar o posicionamento do hotel estudo de caso, com os dois hotéis (A e B) que foram comparados a ele e atenuar as discrepâncias de prestação de serviço do hotel, como exemplo: busca de informações e estabelecimento de negociação estadia/preço/forma de pagamento de forma mais confiável e segura. Mas também, é necessário segurança, sensibilidade, empatia e credibilidade do que será informado e tratado pelos funcionários do hotel na resolução de problemas comuns e rotineiros dos hóspedes.

Em outros casos que requer de atenção individualizada, como exemplo: possibilidade da chegada de um cliente 
especial, é preciso investir na flexibilidade operacional, diluindo a responsabilidade do atendimento para todos os funcionários. Desta forma, quando há o comprometimento de todos para o estabelecimento da qualidade do serviço, a consequência é a imagem positiva e o melhor posicionamento mercadológico do hotel em comparação aos outros na região.

Sheth, Mittal \& Newman (2001, p. 39) afirmam que, "quando as empresas se tornam orientadas para o cliente, elas colhem dois ganhos para o sucesso empresarial, são eles: (i) Elas conquistam uma notável vantagem competitiva no mercado e, (ii) em termos internos, elas tornam-se capazes de cultivar funcionários satisfeitos que se sentem orgulhosos em seus empregos". Agindo desta maneira, o hotel pode envolver e convencer seu cliente através do relacionamento mais próximo, com objetivo de fidelização e de ampliação do relacionamento com a rede de amizade do consumidor. Uma vez que nada supera um atendimento excepcional, ele sempre estará no imaginário do indivíduo como um momento único. Podendo até estabelecer um preço superior, uma vez que a mesma fornece exatamente o que o cliente procura e satisfaz sua necessidade por completo.

O objetivo da fidelização é reter os clientes, evitando que eles migrem para a concorrência, desta forma posicionando a empresa em comparação aos seus concorrentes. É necessário, portanto, um posicionamento competitivo adequado para que o hotel consiga a longo prazo identificar, avaliar e priorizar os atributos de qualidade que são os mais competitivos. Ou seja, elaborando o posicionamento competitivo pelos desdobramentos das necessidades de qualidade em ações.

\section{Análise estatística dos resultados}

O primeiro ponto de avaliação é a comparação da variação da média na avaliação SERVPERF e na importância relativa elaborada pela ferramenta AHP, os quais são obtidos com a resposta às questões dos entrevistados. Nesse caso, é então utilizado o teste t-student como indicador de confiabilidade no uso da média como avaliação proposta por este trabalho. Neste teste se determinar a média de uma população, com graus de liberdade (gl) contabilizados a partir de uma amostra: $\mathrm{n}(\mathrm{gl}=\mathrm{n}-1)$. Neste problema, não se sabe com certeza qual é a média ou o desvio padrão da população, mas ela deve ser normal.
O teste t-student foi escolhido, pois ele parte do pressuposto que o tamanho da amostra (n) é menor que o tamanho da população. Neste caso, tem-se que a amostra é dada por $n$ variáveis aleatórias de distribuição que tende a ser normal, e que elas são independentes $\mathrm{X} 1, \ldots, \mathrm{Xn}$, cuja média amostral é o melhor estimador, que melhor representa a média da população. Para o cálculo é utilizada a variância amostral. Neste caso, o teste $t$-student é elaborado pela Equação 3.

$$
t=\frac{\bar{X}_{n}-\mu}{S_{n} / \sqrt{n}}
$$

Onde: $\bar{X}_{n} \bar{X}_{n}=$ média da amostra;

$$
\mu \mu=\text { valor fixo usado para comparação com }
$$

a média da amostra;

$$
\begin{aligned}
& S n S n=\text { desvio padrão amostral; } \\
& n n=\text { tamanho da amostra. }
\end{aligned}
$$

Para testar a média obtida no SERVPERF que foi 3,82 pontos, tem-se que levar em consideração que o valor de satisfação máxima é 5 pontos e a variação média foi de 0,1789 pontos, então ele será o valor indicativo para testar as duas hipóteses, que são: (i) a hipótese nula, $\mathrm{H}_{0}-\mu=5$ (é satisfação pelo serviço); e a hipótese alternativa, $\mathrm{H}_{1}<5$ (é quando a amostra representa insatisfação pelo serviço). Então o valor $t$ foi de $-14,785$, com $\mathrm{gl}=4$, fato que ocasiona aceitação pela $\mathrm{H}_{0}$, pois o parâmetro de comparação $\alpha(0,01)$ foi que a probabilidade da amostra é menor que 0,0005 , então quando se compara com $\mathrm{p}<0,01$, deve-se aceitar que há satisfação pelo serviço. Para o teste da importância do AHP, a média foi de 0,1428 e a variação média foi de 0,1092 .

Pelo uso do AHP é constatado que se a razão de consistência for menor do que 0,1 pode-se afirmar que há consistência dos dados, este será o parâmetro utilizado para evidenciar a consistência da importância relativa obtida com as sete alternativas. Ou seja, está se fazendo uma análise em que a distribuição $t$ de student apresenta 6 graus de liberdade e queremos usar um nível de confiança de 95\% unicaudal, consultamos a tabela da distribuição e percebeu-se que $\mathrm{t}$ deve ser de 1,895. Isso quer dizer que a probabilidade de 
$-\infty<\mathrm{p}<1,943$ é de $95 \%$, e os valores fora deste intervalo serão desconsiderados ou não aceitos. Neste caso, quando foram utilizados os valores da amostra chegou-se no valor de t em 1,0369 pontos, logo este valor está dentro do intervalo, a hipótese nula está aceita. Comprovando que o decisor não fez um bom julgamento de suas ações quanto ao uso do QFD.

\section{Conclusões}

As alterações no setor hoteleiro faz com que o uso de uma ferramenta que ofereça condições de aliar a voz do cliente ao direcionamento estratégico da empresa seja muito importante. O método QFD preencher essa lacuna e possibilita alinhar os anseios dos clientes e com as alternativas de ação das empresas hoteleiras. Possuindo como maior benefício a modelagem de um serviço adequado à satisfação do cliente.

Para a obtenção dos requisitos dos clientes, esta pesquisa utilizou as cinco dimensões fornecidas pela escala SERVPERF. Desta maneira, foi utilizada como base metodológica para a elaboração do questionário desta pesquisa, que teve por objetivo analisar a percepção dos consumidores quanto aos serviços do hotel estudo de caso. Com base nos resultados coletados, foram elaboradas as alternativas de melhoria do serviço do hotel. E, para o estabelecimento da importância relativa entre as alternativas, foi utilizado o método AHP que tem por função priorizar qual delas é fundamental para a estratégia da empresa de satisfazer o consumidor. O método AHP pode representar o diferencial competitivo frente à concorrência, pois direcionará os esforços do hotel de acordo com os requisitos da demanda e ainda, torna as decisões fornecidas pelo método QFD mais robustas e completas.

De maneira geral, os clientes se sentiram satisfeitos com o serviço prestado pelo hotel estudo de caso, porém, sempre é necessário aperfeiçoar os esforços de melhoria nos pontos mais vulneráveis, evidenciados pela escala SERVPERF, são eles: empatia, segurança, tangibilidade e principalmente a credibilidade dos serviços. Tais esforços são necessários para que os clientes fiquem mais satisfeitos com a qualidade dos serviços prestados hoteleiros. O hotel deste estudo pode incorporar as alternativas que valorizem $\mathrm{O}$ atendimento prestado, com capacitações profissionais dos funcionários.

A maior contribuição desta pesquisa é o aprofundamento do conhecimento sobre os problemas existentes no setor hoteleiro de adequar seus serviços de acordo com a voz dos consumidores, buscando a priorização das alternativas que objetivem melhorar a satisfação dos consumidores e o posicionamento competitivo de um determinado hotel.

Neste sentido, a lacuna de conhecimento que foi preenchida pelos resultados obtidos, é como analisar a compensação das alternativas de melhoria entre elas mesmas, que o gestor faz no ato de posicionar o hotel de forma mais competitiva em detrimento as empresas concorrentes. De forma que o resultado desta avaliação seja a priorização ou uma ordem de implementação das melhorias do projeto do produto/serviço do hotel. E assim, espera-se que os consumidores consigam sentir a melhoria nas dimensões por ele avaliadas como as mais necessárias para a promoção de sua satisfação.

\section{Referências}

AKAO, Y. Quality function deployment: integrating customer requirements into product design. Trad. por Glenn H. Mazur, Cambridge, Productivity Press, 1990.

AQUINO, J. T.; JERÔNIMO, T. B.; MELO, F. J. C. Avaliação da qualidade em serviço de um hotel pelo método SERVPERF. Revista Pensamento Contemporâneo em Administração (UFF), v. 9, p. 127-144, 2015.

BOLTON, R. D.; DREW, J. H. A multistage model of customers' assessment of service quality and value. Journal of Consumer Research, Vol. 17, n. 4, p. 375-84, 1991.

CARDOSO, J.F.; FILHO, N.C.; MIGUEL, P. A. C. Application of Quality Function Deployment for the development of an organic product. Food Quality and Preference. Elsevier, Vol.40, Part A, March, Pages 180-190, 2015.

CASTELLI, G. Excelência em hotelaria: uma abordagem prática. Rio de Janeiro: Qualitymark, 2000. 
CHAMBERS, R.; LEWIS, R. Marketing leadership

in hospitality: Foundations and practices. Van

Nostrand Reinhold: New York, 1989.

CHOW, C.; LUK, P. A strategic service quality approach using analytic hierarchy process.

Managing Service Quality, Vol. 15, n. 3, p. 278 289, 2005.

CHUN, J.; CHO, J. QFD Model Based on a Suitability Assessment for the Reduction of Design Changes in Unsatisfactory Quality. Journal of Asian Architecture and Building Engineering. Vol. 14, n. 1 p. 113-120, 2015.

CLAUSING, D. Total quality development: a stepby-step guide to world-class concurrent engineering, New York, ASME, 1993.

CRONIN, J.; TAYLOR, S. A. Measuring service quality: A reexamination and extension. Journal of Marketing, Vol. 56, n. 3, p. 55-68, 1992.

DENCKER, A. Pesquisa Empírica em Ciências Humanas. São Paulo: Editora Futura, 2008.

EMBRATUR - Instituto Brasileiro de Pesquisa. Cartilha do Sistema Brasileiro de Classificação de Meios de Hospedagem. Ministério do Turismo Impresso no Brasil - Printed in Brazil 2a ed., 2010.

ENSSLIN, L.; MONTIBELLER N., G.; NORONHA, S. M. Apoio à decisão: metodologias para estruturação de problemas e avaliação de alternativas. Florianópolis: Insular, 2001.

FERreira, J. Apostila Processo de Análise Hierárquico (AHP), FEUP / INESC Porto, 2006.

FITZSIMMONS, J. A.; FITZSIMMONS, M. J. Administração de serviços: operações, estratégia e tecnologia da informação. Porto Alegre: Bookman, 6.ed., 2010.

GARVIN, D. A. Managing quality. New York: The Free Press, 1988.

GODOY, A. S. Estudo de Caso qualitativo. In: Pesquisa qualitativa em estudos organizacionais: paradigmas, estratégias e métodos. Godoy, C. K., Bandeira-de-Melo, R., \& Silva, A. B.; (org). São Paulo:
Saraiva. p. 115-143, 2010.

IBGE - Instituto Brasileiro de Geografia e Estatística. Pesquisa de Serviços de Hospedagem. 2011. Disponível em: http:/ / ftp.ibge.gov.br/ Comercio_e_Servicos/Pesquisa_Servicos_de_ Hospedagem/2011/psh2011.pdf. Acessado em: $22 / 02 / 2015$.

LOCKAMY III, A.; KHURANA, A. Quality function deployment: a case study, Production and Inventory Management Journal, Vol.36, No.2, pp.56-60, 1995.

MATTOS, P. L. C. L. Análise de entrevistas não estruturadas: da formalização à pragmática da linguagem. In: Pesquisa qualitativa em estudos organizacionais: paradigmas, estratégias e métodos. GODOI, C. K.; BANDEIRA-DE-MELO, R.; SILVA, A. B.; (org). São Paulo: Saraiva. p. 347-401, 2010.

MORGAN, G.; SMIRCICH, L. The case for qualitative research. Academy of Management Review, Vol.5, n.4, p.491-500, 1980.

\section{NORMANN, R. Administração de serviços:} estratégia e liderança na empresa de serviços. São Paulo: Atlas, 1993.

PARASURAMAN, A.; ZEITHAML, A.; BERRY, L. A conceptual model of service quality and its implications for future research. Journal of Marketing, Vol. 46, n. 4, p. 41-50, 1985.

PARASURAMAN, A.; ZEITHAML, A.; BERRY, L. SERVQUAL: a multiple-item scale for measuring costumer perceptions of service quality. Journal of Retailing, v. 64, n. 1, p. 12-29, 1988.

SAATY, T. Decision making with the analytic hierarchy process. International Journal of Services Sciences, Vol. 1, n. 1, p. 83-97, 2008.

SAATY, T. Fundamentals of decision making priority theory with the analytic hierarchy process. 2. ed. RWS Publications, 2001.

SAATY, T. How to make a decision: The Analytic Hierarchy Process. European Journal of Operational Research, Vol. 48, n. 1, p. 9 26, 1990. 
SAATY, T. L. The analytic hierarchy process.

New York: McGraw-Hill, 1980.

SHIMIZU, T. Decisão nas organizações. $3^{\text {a }}$ edição. Editora Atlas, 2010.

SHETH, J. N.; MITTAL, B.; NEWMAN, B. Comportamento do Cliente: indo além do comportamento do consumidor. São Paulo: Atlas, 2001.

SILVA, D. M. R. Aplicação do Método AHP para avaliação de projetos industriais. 2007. 131f.

Dissertação (Mestrado em Engenharia Industrial) Departamento de Engenharia Industrial, Pontifícia Universidade Católica do Rio de Janeiro, Rio de Janeiro.

SILVA, L. M.; MEDEIROS, C. A.; COSTA, B. K. Qualidade dos Serviços Turísticos no Setor de Restaurantes: uma aplicação do modelo SERVPERF. Revista Hospitalidade, Vol. 6, n. 2, p.115-139, 2009.

SULLIVAN, L.P. Quality function deployment, Quality Progress, Vol.19, No.6, pp.39-50, 1986.

VARGO, S. L.; LUSH, R. F. Service-dominant logic: continuing the evolution. Journal of the Academic Marketing Science, Vol. 36, n. 1, p.1-10, 2008.

VELJKO, M.; SENI, V.; MIMOVI, P. Factors affecting choice and image of ethnic restaurants in Serbia, British Food Journal, Vol. 117 Iss 7 pp.., 2015.

YIN, R. Estudo de Caso: planejamento e métodos. 5.ed. Bookman. Porto Alegre, 2015.

ZEITHAML, V. A.; PARASURAMAN A.; BERRY, L.L. Problems and Strategies in Services Marketing. Journal of Marketing. Vol. 49, n. 1, p. 33 - 46, 1985. 


\section{APÊNDICE 1. Questionário do Estudo de Caso}

\section{Questionário}

Profissão:

Idade: anos

Casado?: SIM ( ) NÃO () Tem filhos SIM ( ), quantos? $\mathrm{NÃO}()$

Motivo da viagem: Sexo: $\mathrm{F}() \mathrm{M}()$

Qual o seu nivel de escolaridade?Sou apenas alfabetizado( ) $1^{\circ}$ Grau incompleto ( ) $1^{\circ}$ Grau completo ( ) $2^{\circ}$ Grau incompleto () $2^{\circ}$ Grau completo () $3^{\circ}$ Grau incompleto () $3^{\circ}$ Grau completo () Pós-graduação ()

Onde você reside?

Há quanto tempo você é cliente deste pousada?

Você já utilizou o(s) mesmo(s) serviço(s) em outros hotéis? SIM ( ) NÃO ()

Frequência de estadia em hotéis: ( ) semanal ( ) quinzenal ( ) mensal

3 vezes no ano ( ) 2 vezes no ano ( ) anual

1. INSTRUÇÕES: Responda de acordo com sua percepção sobre os SERVIÇOS PRESTADOS DO HOTEL, Para cada uma das afirmações indique: número 1(L),discorda totalmente que a pousada tenha alcançado a característica; 5 (J), concorda totalmente que atingiu a característica.

\begin{tabular}{|l|l|l|l|l|l|}
\hline $\begin{array}{l}\text { LEGENDA: J= Concordo totalmente } \\
\text { L= Discordo totalmente }\end{array}$ & $1 \mathrm{~L}$ & 2 & $3 \mathrm{~K}$ & 4 & $5 \mathrm{~J}$ \\
\hline $\begin{array}{l}\text { 1. A Pousada no qual está hospedado possui equipamentos modernos e atualizados: } \\
\text { móveis, elevador, TV, internet, ar-condicionado. }\end{array}$ & 1 & 2 & 3 & 4 & 5 \\
\hline 2. O ambiente físico e as instalações deste hotel são harmoniosos, limpos e agradáveis. & 1 & 2 & 3 & 4 & 5 \\
\hline 3. Este hotel é bem localizado e é de fácil acesso & 1 & 2 & 3 & 4 & 5 \\
\hline 4. Este hotel tem manutenção adequada: camas, banheiros, área de lazer & 1 & 2 & 3 & 4 & 5 \\
\hline 5. Este hotel transmite todas as informações necessárias de forma confiável e precisa & 1 & 2 & 3 & 4 & 5 \\
\hline 6. Este hotel executa os serviços no tempo prometido & 1 & 2 & 3 & 4 & 5 \\
\hline 7. Este hotel guarda os registros dos seus clientes de forma correta: reservas, pedidos. & 1 & 2 & 3 & 4 & 5 \\
\hline $\begin{array}{l}\text { 8. Os administradores do hotel estão envolvidos e comprometidos com a qualidade e a } \\
\text { melhoria dos serviços prestados }\end{array}$ & 1 & 2 & 3 & 4 & 5 \\
\hline $\begin{array}{l}\text { 9. Este hotel concede ao cliente, de forma exata, a data ou horário de quando o serviço } \\
\text { será prestado. }\end{array}$ & 1 & 2 & 3 & 4 & 5 \\
\hline 10. Os funcionários do hotel possuem sempre boa vontade em ajudar seus clientes & 1 & 2 & 3 & 4 & 5 \\
\hline $\begin{array}{l}\text { 11. Os funcionários do hotel agem com disponibilidade e prontidão para atender os } \\
\text { clientes }\end{array}$ & 1 & 2 & 3 & 4 & 5 \\
\hline $\begin{array}{l}\text { 12. Os funcionários do hotel passam confiança para os clientes durante a prestação do } \\
\text { serviço }\end{array}$ & 1 & 2 & 3 & 4 & 5 \\
\hline
\end{tabular}




\begin{tabular}{|c|c|c|c|c|c|}
\hline 13. Os funcionários do hotel são corteses no atendimento aos clientes & 1 & 2 & 3 & 4 & 5 \\
\hline $\begin{array}{l}\text { 14. Os funcionários do hotel possuem conhecimento necessário para execução dos } \\
\text { serviços }\end{array}$ & 1 & 2 & 3 & 4 & 5 \\
\hline 15. O atendimento aos clientes é personalizado & 1 & 2 & 3 & 4 & 5 \\
\hline 16. Os funcionários do hotel sabem ouvir atentamente as solicitações dos clientes & 1 & 2 & 3 & 4 & 5 \\
\hline 17. O hotel possui procedimentos padronizados & 1 & 2 & 3 & 4 & 5 \\
\hline 18. Os problemas dos clientes são resolvidos & 1 & 2 & 3 & 4 & 5 \\
\hline $\begin{array}{l}\text { 19. Os funcionários do hotel têm disponibilidade de tempo para atendimento adequado } \\
\text { e individual. }\end{array}$ & 1 & 2 & 3 & 4 & 5 \\
\hline 20. Os funcionários do hotel têm boa aparência & 1 & 2 & 3 & 4 & 5 \\
\hline $\begin{array}{l}\text { 21. A comunicação do hotel (internet, telefone) é de fácil compreensão e utilização pelos } \\
\text { clientes. }\end{array}$ & 1 & 2 & 3 & 4 & 5 \\
\hline $\begin{array}{l}\text { 22. Os funcionários do hotel têm segurança ao negociar problemas de atendimento com } \\
\text { os clientes. }\end{array}$ & 1 & 2 & 3 & 4 & 5 \\
\hline
\end{tabular}

\section{Por favor, marque seu grau de satisfação em comparação a outros dois hotéis e com o hotel estudo} de caso.

\begin{tabular}{|l|c|c|c|c|c|}
\hline $\begin{array}{l}\text { Seu grau de Satisfação: J Extremamente satisfeito } \\
\text { L= Totalmente insatisfeito }\end{array}$ & $1 \mathrm{~L}$ & 2 & $3 \mathrm{~K}$ & 4 & $5 \mathrm{~J}$ \\
\hline Nome do HOTEL A - fornecido pela pesquisa & 1 & 2 & 3 & 4 & 5 \\
\hline Nome do HOTEL B - fornecido pela pesquisa & 1 & 2 & 3 & 4 & 5 \\
\hline Nome do Hotel estudo de caso - fornecido pela pesquisa & 1 & 2 & 3 & 4 & 5 \\
\hline
\end{tabular}

